\title{
Protection Group
}

National Cancer Institute

\section{Source}

National Cancer Institute. Protection Group. NCI Thesaurus. Code C42706.

This class represents a Protection Group. It is nothing but a collection of protection elements. A user or a user-group can assume various roles on a protection group. 